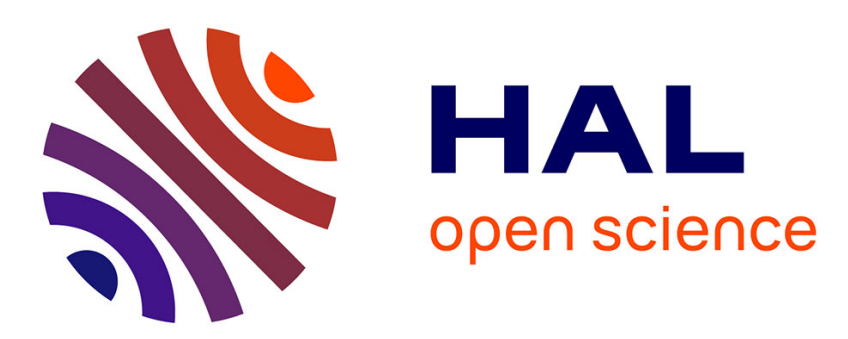

\title{
Recent trends in primary antimicrobial resistance of in Finland
}

Pirkko Kostamo, Lea Veijola, Aino Oksanen, Seppo Sarna, Hilpi Rautelin

\section{To cite this version:}

Pirkko Kostamo, Lea Veijola, Aino Oksanen, Seppo Sarna, Hilpi Rautelin. Recent trends in primary antimicrobial resistance of in Finland. International Journal of Antimicrobial Agents, 2010, 37 (1), pp.22. 10.1016/j.ijantimicag.2010.09.013 . hal-00651648

\section{HAL Id: hal-00651648 \\ https://hal.science/hal-00651648}

Submitted on 14 Dec 2011

HAL is a multi-disciplinary open access archive for the deposit and dissemination of scientific research documents, whether they are published or not. The documents may come from teaching and research institutions in France or abroad, or from public or private research centers.
L'archive ouverte pluridisciplinaire HAL, est destinée au dépôt et à la diffusion de documents scientifiques de niveau recherche, publiés ou non, émanant des établissements d'enseignement et de recherche français ou étrangers, des laboratoires publics ou privés. 


\section{Accepted Manuscript}

Title: Recent trends in primary antimicrobial resistance of Helicobacter pylori in Finland

Authors: Pirkko Kostamo, Lea Veijola, Aino Oksanen, Seppo Sarna, Hilpi Rautelin

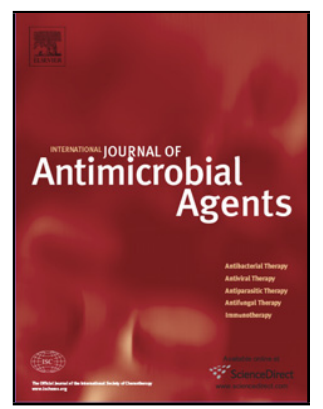

PII:

S0924-8579(10)00440-1

DOI: doi:10.1016/j.ijantimicag.2010.09.013

Reference: ANTAGE 3444

To appear in: International Journal of Antimicrobial Agents

Received date: $\quad 13-6-2010$

Revised date: $\quad 16-8-2010$

Accepted date: $\quad$ 27-9-2010

Please cite this article as: Kostamo P, Veijola L, Oksanen A, Sarna S, Rautelin H, Recent trends in primary antimicrobial resistance of Helicobacter pylori in Finland, International Journal of Antimicrobial Agents (2010), doi:10.1016/j.ijantimicag.2010.09.013

This is a PDF file of an unedited manuscript that has been accepted for publication. As a service to our customers we are providing this early version of the manuscript. The manuscript will undergo copyediting, typesetting, and review of the resulting proof before it is published in its final form. Please note that during the production process errors may be discovered which could affect the content, and all legal disclaimers that apply to the journal pertain. 


\section{Recent trends in primary antimicrobial resistance of Helicobacter pylori in Finland}

Pirkko Kostamo $^{a, b, \star}$, Lea Veijola ${ }^{a, b}$, Aino Oksanen ${ }^{a, b}$, Seppo Sarna ${ }^{c}$, Hilpi Rautelin ${ }^{\text {b,d,e }}$

${ }^{a}$ Helsinki Health Care, Kettutie 8 M, 00800 Helsinki, Finland

${ }^{\mathrm{b}}$ Department of Bacteriology and Immunology, Haartman Institute, University of

Helsinki, Helsinki, Finland

${ }^{c}$ Department of Public Health, University of Helsinki, Helsinki, Finland

${ }^{d}$ HUSLAB, Helsinki University Central Hospital Laboratory, Helsinki, Finland

e Department of Medical Sciences, University of Uppsala, Uppsala, Sweden

ARTICLE INFO

Article history:

Received 13 June 2010

Accepted 27 September 2010

Keywords:

Helicobacter pylori

Drug resistance

Microbial

Antibacterial agents 
* Corresponding author. Tel.: +358 93105512.

E-mail address: pirkko.kostamo@gmail.com (P. Kostamo). 


\section{ABSTRACT}

The antimicrobial susceptibility of Helicobacter pylori is an important predictor of the success of eradication therapy. To evaluate recent changes in primary antimicrobial resistance of $H$. pylori isolated from Finnish patients, the clinical records of $H$. pyloripositive patients referred for endoscopy to Herttoniemi Hospital (Helsinki, Finland) during 2000-2008 were investigated retrospectively. Stored H. pylori strains from 505 patients without previous eradication therapy were tested for clarithromycin, metronidazole, levofloxacin, tetracycline and amoxicillin susceptibility by Etest. Data on local consumption of antimicrobials were collected and correlations between consumption and resistance were calculated. During the 9-year study period, metronidazole resistance was high (range $29-59 \%$, overall $41 \%$ ). After an initial increase in clarithromycin resistance (0\% in 2000 to $16 \%$ in 2003), resistance to clarithromycin decreased to $4 \%$ in 2008 . No significant correlation was detected between consumption of macrolides and resistance of clarithromycin. Resistance to levofloxacin varied between $0 \%$ and $12 \%$. Primary metronidazole resistance in $\mathrm{H}$. pylori is at a high level, however levofloxacin and clarithromycin resistances are still at a reasonable level. Thus, primary clarithromycin resistance in $H$. pylori in Finland has not become such a problem as in many other countries. Primary resistance to the antimicrobials studied varied considerably from year to year. 


\section{Introduction}

Helicobacter pylori is a major causative agent of gastroduodenal diseases such as chronic gastritis, peptic ulcer disease, gastric cancer and mucosa-associated lymphoid tissue (MALT) lymphoma [1-3]. The infection is typically acquired in childhood or early adolescence [4]. According to the latest European recommendations, eradication therapy is recommended in peptic ulcer disease, MALT lymphoma, atrophic gastritis, unexplained iron deficiency anaemia and chronic idiopathic thrombocytopenic purpura as well as in first-degree relatives of patients with gastric cancer [5]. Standard eradication therapy is based on a combination of a proton pump inhibitor and two antimicrobials, with clarithromycin being recognised as the key component [6]. However, an increasing number of $H$. pylori isolates worldwide show resistance to clarithromycin, which is considered the main cause of eradication failure $[7,8]$. If the local primary resistance rates to clarithromycin exceed $15-20 \%$, empirical treatment with this agent is no longer recommended [5]. Metronidazole resistance is even more common, although metronidazole resistance in vitro does not always predict treatment failure [9]. Resistance to amoxicillin and tetracycline, two further components useful in combined therapy, has remained at a low level, whereas recent studies suggest an increasing trend in primary fluoroquinolone resistance $[10,11]$. However, so far the fluoroquinolones, such as levofloxacin, have been successfully used in $H$. pylori salvage therapy in patients with previous eradication failure [12-15]. 
The antimicrobial susceptibility of $H$. pylori is an important predictor of the success of eradication therapy. Choosing the most effective first-line therapy for $\mathrm{H}$. pylori infection is critical, as higher eradication rates are usually obtained in the first attempt to treat this chronic infection whereas the following therapies are hampered by problems caused by secondary resistance [6]. Antimicrobial susceptibility tests are rarely available to aid decisions regarding first-line therapy. Even according to the latest guidelines, antimicrobial susceptibility testing is first recommended after therapy failure [5]. This emphasises the need for knowledge of the local primary antimicrobial resistance situation. However, clinicians are usually unaware of the prevalence of antimicrobial resistance among $H$. pylori isolates in their region, resulting in poorer cure rates. Local resistance rates also appear to change dynamically owing to changes in annual antibiotic consumption [16] and may even vary with geographical, gender and age differences and therefore require constant monitoring $[6,17]$.

In Finland, the prevalence of primary clarithromycin resistance (before any eradication attempts) was as low as $2 \%$ in $2000-2001$, whereas metronidazole resistance was $38 \%$ [18], this latter figure being in line with some early reports [9]. The aim of this study was to evaluate the recent possible changes in primary antimicrobial resistance of $H$. pylori isolated from Finnish patients during a 9-year period to determine whether increasing resistance trends reported from elsewhere could be detected. 


\section{Patients and methods}

\subsection{Patients}

Clinical records of consecutive H. pylori-positive patients referred for endoscopy on clinical indications to Herttoniemi Hospital (Helsinki, Finland) during 2000-2008 were investigated retrospectively. Of $3045 \mathrm{H}$. pylori cultures taken in 6774 gastroscopies during the study period, 1037 were $H$. pylori-positive. In order to assess primary antimicrobial resistance, patients previously treated for $H$. pylori were excluded from the study; thus, 505 patients with $H$. pylori isolates available were enrolled. The median age of patients was 62 years (range 18-92 years), $45 \%$ of patients were male and $16 \%$ were of foreign origin. Permission to explore the patient files was allowed by the authorities of Helsinki Health Center.

\subsection{Bacterial isolates and antimicrobial susceptibility testing}

Helicobacter pylori isolates had originally been identified on the basis of colony appearance, Gram staining and positive reactions in catalase, oxidase and urease tests. Bacterial isolates were kept frozen at $-70^{\circ} \mathrm{C}$ before analysis. Only one isolate per patient was included in the study. Antimicrobial susceptibility testing was performed by Etest (AB BIODISK, Solna, Sweden). Minimal inhibitory concentrations (MICs) were determined for clarithromycin, metronidazole, levofloxacin, tetracycline and amoxicillin. The inoculum was prepared from a 2-day-old or 3-day-old culture grown on a blood agar plate, and the bacterial suspension in Brucella broth was adjusted to match the turbidity 
equivalent to a McFarland 3 standard. Freshly prepared plates (BBL ${ }^{\mathrm{TM}}$ Mueller Hinton II Agar; BD, Le Pont de Claix, France) supplemented with 10\% horse blood and used within 7 days of preparation were inoculated with the suspension and then Etest strips (one strip per agar plate) were added. The agar plates were incubated at $35^{\circ} \mathrm{C}$ in a microaerobic atmosphere $\left(\mathrm{BBL}^{\mathrm{TM}}\right.$ CampyPak $^{\mathrm{TM}}$ Plus microaerophilic system; $\mathrm{BD}$, Sparks, MD) for $72 \mathrm{~h}$. MIC values were determined according to the manufacturer's instructions and were read where the inhibition zone ellipse intersected the strip. The following interpretive criteria for resistance were used: clarithromycin, $>1 \mu \mathrm{g} / \mathrm{mL}$; metronidazole, $>8 \mu \mathrm{g} / \mathrm{mL}$; levofloxacin, $>1 \mu \mathrm{g} / \mathrm{mL}$; tetracycline, $>1 \mu \mathrm{g} / \mathrm{mL}$; and amoxicillin, $>0.5 \mu \mathrm{g} / \mathrm{mL}$.

\subsection{Antimicrobial consumption}

Data on the regional consumption of antimicrobial drugs were obtained from the Finnish Medicines Agency FIMEA. Sales statistics were based on total sales, including both hospitals and pharmacies, on an annual basis. Antimicrobial consumption was expressed as defined daily doses per 1000 inhabitants per day.

\subsection{Statistical methods}

Differences in demographic data were analysed with the $\chi^{2}$ test using GraphPad Software (GraphPad QuickCalcs Online Calculators for Scientists; http://www.graphpad.com/quickcalcs/index.cfm). Associations between consumption of 
different antimicrobials and resistance of $H$. pylori to the different antimicrobials were analysed using Pearson correlation coefficients, and time trends were analysed using linear regression models. Data were analysed using SPSS software version 17.0 (SPSS Inc., Chicago, IL). Statistical significance was set at level of 0.05 (two-tailed).

\section{Results}

All H. pylori isolates were susceptible to amoxicillin [MIC for $90 \%$ of the isolates ( $\mathrm{MIC}_{90}$ ) $<0.016 \mu \mathrm{g} / \mathrm{mL}$ ], and only one tetracycline-resistant isolate was observed $(\mathrm{MIC}=1.5$ $\mu \mathrm{g} / \mathrm{mL}$ ). The overall prevalence of clarithromycin resistance was $8 \%$ during the 9 -year study period, ranging from $0 \%$ (in 2000) to 16\% (in 2003). The increase in clarithromycin resistance did not reach significance in the study period. Levofloxacin resistance varied between $0 \%$ and $12 \%$ (overall $7 \%$ ), and metronidazole resistance varied between $29 \%$ and $59 \%$ (overall $41 \%$ ) (Fig. 1.) Resistance to metronidazole was significantly more common in women than in men $(49 \%$ vs. $31 \%$, respectively; $P<0.001)$. Women were also more likely than men to harbour clarithromycin-resistant $H$. pylori $(10.2 \%$ vs. $5.2 \%$, respectively; $P=0.035$ ). No significant age- or origin-related differences in resistance rates were found.

The overall prevalence of resistance to at least two antimicrobials was $7 \%(33 / 505)$; the most common type of multiresistance detected was to clarithromycin and metronidazole (48\%; 16/33), followed by levofloxacin and metronidazole (33\%; 11/33). Resistance to three different antimicrobial agents was also observed, although only in two isolates. 
Fig. 2 shows the annual consumption of macrolides, fluoroquinolones and metronidazole in the hospital district of Helsinki and Uusimaa during the study period. Annual consumption of macrolides including clarithromycin showed a significant decrease in the study area during the 9-year period $(P=0.007)$ but there was no significant correlation between macrolide consumption and resistance to clarithromycin. However, there was a positive correlation between consumption of fluoroquinolones and resistance to clarithromycin $(P=0.001)$. During the 9-year study period there was a significant increase in the consumption of metronidazole $(P=0.013)$, however despite this no significant increase in metronidazole resistance was detected.

\section{Discussion}

In contrast to many reports from other countries, primary clarithromycin resistance in $\mathrm{H}$. pylori has not become a problem in the study area despite the rapidly increasing resistance rates during 2002-2003. After 2006, primary clarithromycin resistance rates have even been decreasing (Fig. 1). Levofloxacin resistance has been fluctuating close to the $10 \%$ level during the latest study years.

In the present study, the prevalence of primary metronidazole resistance was at a high level and was significantly higher in women than in men. The latter finding is in accordance with many earlier studies $[6,18]$. Resistance to levofloxacin did not show any gender differences in this study, whereas clarithromycin resistance was significantly 
more common in women than in men. Some recent studies have also revealed this kind of gender difference with regard to clarithromycin resistance $[8,17,19]$.

During the 9-year observation in the study area, macrolide consumption decreased significantly, but there was no significant correlation between consumption of macrolides and resistance to clarithromycin. A recent study showed that rates of resistance in $H$. pylori to clarithromycin and metronidazole decreased following government policy to restrict the use of antimicrobial agents for infectious diseases [20]. Earlier in Finland, a significant decline in the frequency of erythromycin resistance among group A streptococci was observed following nationwide reductions in the use of macrolide antibiotics for outpatient therapy [21]. A statistically significant association also existed between regional erythromycin resistance in Streptococcus pyogenes and consumption of macrolides [22]. However, the recent decrease in antimicrobial consumption may not necessarily be reflected in the susceptibility of an $H$. pylori isolate that has infected the gastric mucosa for decades.

Consumption of fluoroquinolones remained at a stable level, although in this study the primary resistance rates to fluoroquinolones showed an increasing tendency. However, primary levofloxacin resistance of $H$. pylori in Finland is still at a reasonably low level.

The breakpoints used for resistance to clarithromycin have slightly varied in different studies, ranging from $>0.5 \mu \mathrm{g} / \mathrm{mL}$ to $>2 \mu \mathrm{g} / \mathrm{mL}[16,19,20,23-25]$. In this study, the breakpoint for resistance to clarithromycin was set at $>1 \mu \mathrm{g} / \mathrm{mL}$ and the separation 
between clarithromycin-susceptible and -resistant isolates was quite clear-cut as there were only 9 isolates (2\%) (distributed evenly in the study period) with clarithromycin MICs between $0.75 \mu \mathrm{g} / \mathrm{mL}$ and $2 \mu \mathrm{g} / \mathrm{mL}$.

Effective therapy for $H$. pylori should achieve an intention-to-treat eradication rate of $\geq 80 \%$ [26]. However, during the past years increasing antimicrobial resistance has complicated therapy and the usual cure rates have been lower than those considered acceptable for other serious, treatable bacterial infections [26]. Therefore, empirical use of eradication therapies should be based on a knowledge of antimicrobial drug resistance. Maastricht guidelines recommend local reference centres to monitor antimicrobial resistance and eradication rates within countries in order to determine the best treatment regimens [5]. However, considerable fluctuation in primary antimicrobial resistance from year to year, as also shown in the present study, should be taken into account when results from cross-sectional studies form the basis for treatment guidelines.

In conclusion, this 9-year study showed a slight increasing tendency of primary clarithromycin resistance of $H$. pylori in Finland; however, the resistance rates were still at the level where clarithromycin-containing triple therapies could be used empirically. Furthermore, during the past 2 years clarithromycin resistance rates have even been declining. Metronidazole resistance has remained approximately at the same level as in early $2000[18,23]$. There are no earlier studies regarding primary fluoroquinolone resistance of $H$. pylori in Finland, but according to the present findings the mean 
resistance rate $(7 \%)$ was lower than that observed in many other countries, with values ranging from $14.4 \%$ up to $22.1 \%$ [27]. In the near future, regional treatment regimens based on local antimicrobial resistance may improve eradication results for $H$. pylori.

\section{Acknowledgments}

The authors warmly thank researcher Tinna Voipio, BSc (Pharm) from FIMEA for the sales statistics. The skilful technical assistance of Mr Marko Haverinen is gratefully acknowledged. The isolates from 2008 were tested as part of the third European multicentre study on antibiotic susceptibility of Helicobacter pylori. For these particular isolates, Etests were kindly provided by AB BIODISK (Solna, Sweden). Part of this study was presented at the XXIInd International Workshop on Helicobacter and Related Bacteria in Chronic Digestive Inflammation and Gastric Cancer, Porto, Portugal, 17-19 September 2009.

\section{Funding}

None.

\section{Competing interests}

None declared.

\section{Ethical approval}

Permission to explore the patient files was allowed by the authorities of Helsinki Health Center. 
Page 13 of 20 


\section{References}

[1] Dixon MF. Patterns of inflammation linked to ulcer disease. Baillieres Best Pract Res Clin Gastroenterol 2000;14:27-40.

[2] Parsonnet J, Hansen S, Rodriguez L, Gelb AB, Warnke RA, Jellum E, et al. Helicobacter pylori infection and gastric lymphoma. N Engl J Med 1994;330:126771.

[3] Suerbaum S, Michetti P. Helicobacter pylori infection. N Engl J Med 2002;347:117586.

[4] Malaty HM, Graham DY, Klein PD, Evans DG, Adam E, Evans DJ. Transmission of Helicobacter pylori infection. Studies in families of healthy individuals. Scand J Gastroenterol 1991;26:927-32.

[5] Malfertheiner P, Megraud F, O'Morain C, Bazzoli F, El-Omar E, Graham D, et al. Current concepts in the management of Helicobacter pylori infection: the Maastricht III Consensus Report. Gut 2007;56:772-81.

[6] Mégraud F. H pylori antibiotic resistance: prevalence, importance, and advances in testing. Gut 2004;53:1374-84.

[7] Horiki N, Omata F, Uemura M, Suzuki S, Ishii N, lizuka Y, et al. Annual change of primary resistance to clarithromycin among Helicobacter pylori isolates from 1996 through 2008 in Japan. Helicobacter 2009;14:86-90.

[8] De Francesco V, Margiotta M, Zullo A, Hassan C, Giorgio F, Burattini O, et al. Prevalence of primary clarithromycin resistance in Helicobacter pylori strains over a 15 year period in Italy. J Antimicrob Chemother 2007;59:783-5. 
[9] Rautelin H, Seppälä K, Renkonen OV, Vainio U, Kosunen TU. Role of metronidazole resistance in therapy of Helicobacter pylori infections. Antimicrob Agents Chemother 1992;36:163-6.

[10] Zullo A, Perna F, Hassan C, Ricci C, Saracino I, Morini S, et al. Primary antibiotic resistance in Helicobacter pylori strains isolated in northern and central Italy. Aliment Pharmacol Ther 2007;25:1429-34.

[11] Hung KH, Sheu BS, Chang WL, Wu HM, Liu CC, Wu JJ. Prevalence of primary fluoroquinolone resistance among clinical isolates of Helicobacter pylori at a university hospital in Southern Taiwan. Helicobacter 2009;14:61-5.

[12] Wolle K, Malfertheiner P. Treatment of Helicobacter pylori. Best Pract Res Clin Gastroenterol 2007;21:315-24.

[13] Egan BJ, Katicic M, O'Connor HJ, O'Morain CA. Treatment of Helicobacter pylori. Helicobacter 2007;12(Suppl 1):31-7.

Coelho LG, Moretzsohn LD, Vieira WL, Gallo MA, Passos MC, Cindr JM, et al. New once-daily, highly effective rescue triple therapy after multiple Helicobacter pylori treatment failures: a pilot study. Aliment Pharmacol Ther 2005;21:783-7. Wong WM, Gu Q, Chu KM, Yee YK, Fung FM, Tong TS, et al.

Lansoprazole, levofloxacin and amoxicillin triple therapy vs. quadruple therapy as second-line treatment of resistant Helicobacter pylori infection. Aliment Pharmacol Ther 2006;23:421-7. Perez Aldana L, Kato M, Nakagawa S, Kawarasaki M, Nagasako T, Mizushima $\mathrm{T}$, et al. The relationship between consumption of antimicrobial agents 
and the prevalence of primary Helicobacter pylori resistance. Helicobacter $2002 ; 7: 306-9$.

$[17]$

Kobayashi I, Murakami K, Kato M, Kato S, Azuma T, Takahashi S, et al.

Changing antimicrobial susceptibility epidemiology of Helicobacter pylori strains in Japan between 2002 and 2005. J Clin Microbiol 2007;45:4006-10.

[18]

Koivisto TT, Rautelin HI, Voutilainen ME, Niemelä SE, Heikkinen M,

Sipponen PI, et al. Primary Helicobacter pylori resistance to metronidazole and clarithromycin in the Finnish population. Aliment Pharmacol Ther 2004;19:1009-17. Osato MS, Reddy R, Reddy SG, Penland RL, Malaty HM, Graham DY. Pattern of primary resistance of Helicobacter pylori to metronidazole or clarithromycin in the United States. Arch Intern Med 2001;161:1217-20. Poon SK, Lai CH, Chang CS, Lin WY, Chang YC, Wang HJ, et al.

Prevalence of antimicrobial resistance in Helicobacter pylori isolates in Taiwan in relation to consumption of antimicrobial agents. Int J Antimicrob Agents $2009 ; 34: 162-5$. Seppälä H, Klaukka T, Vuopio-Varkila J, Muotiala A, Helenius H, Lager K, et al. The effect of changes in the consumption of macrolide antibiotics on erythromycin resistance in group A streptococci in Finland. Finnish Study Group for Antimicrobial Resistance. N Engl J Med 1997;337:441-6. Bergman M, Huikko S, Pihlajamäki M, Laippala P, Palva E, Huovinen P, et al.; Finnish Study Group for Antimicrobial Resistance (FiRe Network). Effect of macrolide consumption on erythromycin resistance in Streptococcus pyogenes in Finland in 1997-2001. Clin Infect Dis 2004;38:1251-6. 
[23] Glupczynski Y, Mégraud F, Lopez-Brea M, Andersen LP. European

multicentre survey of in vitro antimicrobial resistance in Helicobacter pylori. Eur J Clin Microbiol Infect Dis 2001;20:820-3.

[24] Storskrubb T, Aro P, Ronkainen J, Wreiber K, Nyhlin H, Bolling-Sternevald E, et al. Antimicrobial susceptibility of Helicobacter pylori strains in a random adult Swedish population. Helicobacter 2006;11:224-30. Raymond J, Lamarque D, Kalach N, Chaussade S, Burucoa C. High level of antimicrobial resistance in French Helicobacter pylori isolates. Helicobacter 2010;15:21-7.

[26] Graham DY, Shiotani A. New concepts of resistance in the treatment of Helicobacter pylori infections. Nat Clin Pract Gastroenterol Hepatol 2008;5:321-31. [27] Bogaerts P, Berhin C, Nizet H, Glupczynski Y. Prevalence and mechanisms of resistance to fluoroquinolones in Helicobacter pylori strains from patients living in Belgium. Helicobacter 2006;11:441-5. 
Fig. 1. Antimicrobial resistance of Helicobacter pylori isolates during the study period.

Fig. 2. Annual consumption of macrolides, fluoroquinolones and metronidazole in the hospital district of Helsinki and Uusimaa (Finland). DDD/1000 inh/day, defined daily doses per 1000 inhabitants per day. 


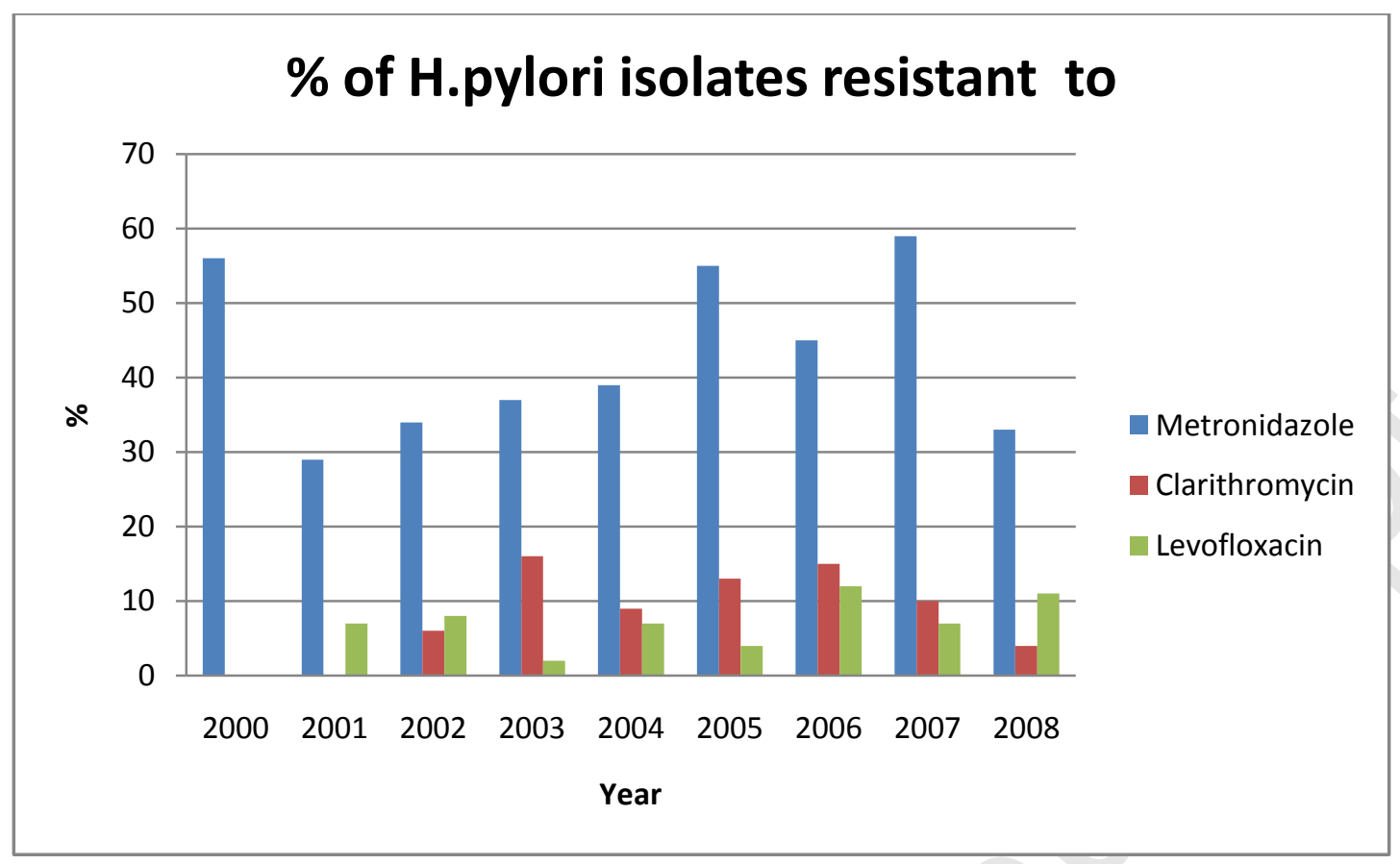




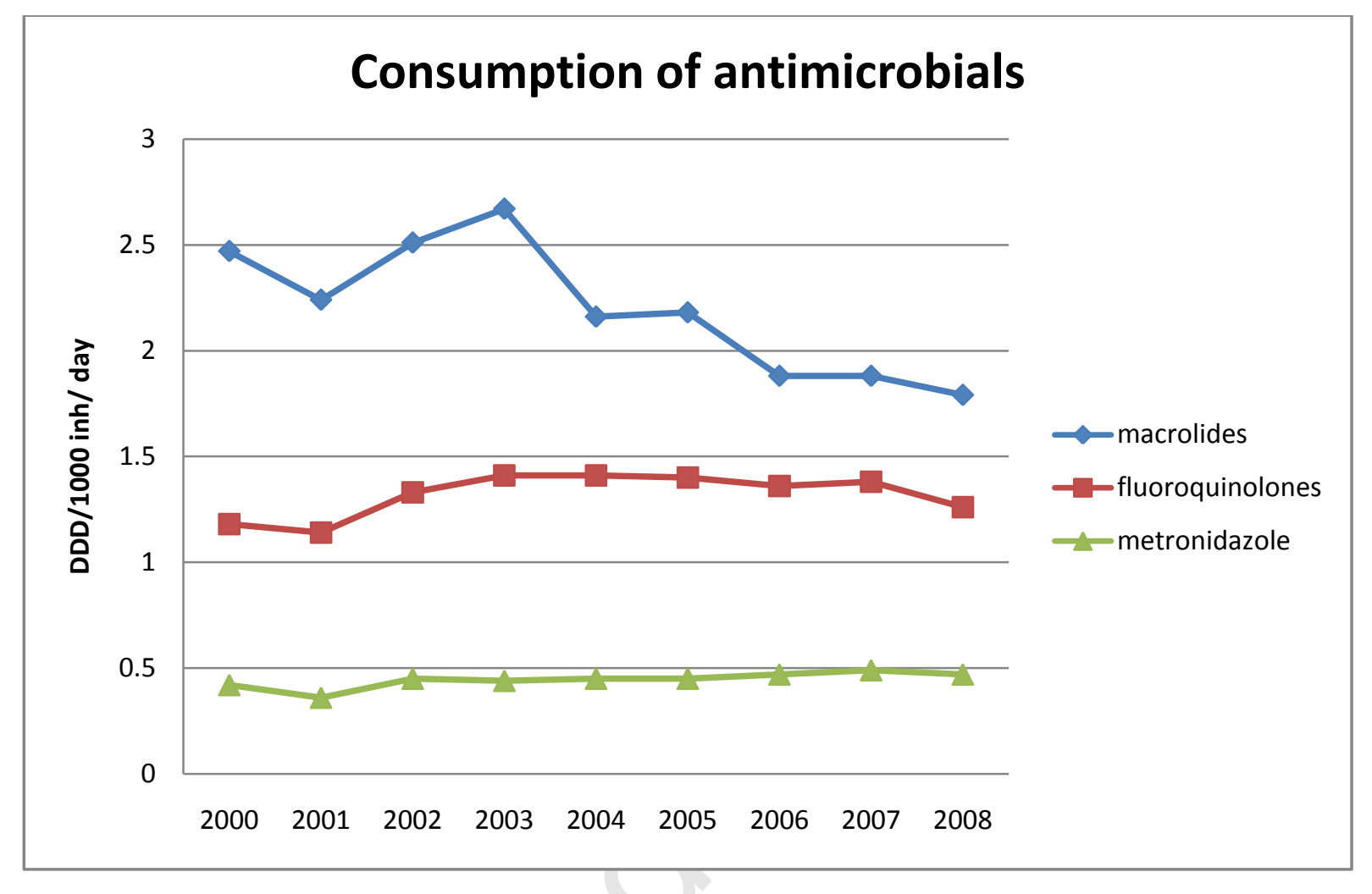

Consumption of antimicrobials

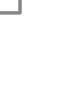

.

